\title{
Comparison of Pneumococcal Avidity and Antibody Concentration in Children with Recurrent Infections: A Retrospective Pilot Study
}

\author{
Sara B. Intner ${ }^{1}$, Michelle Altrich ${ }^{2}$, Niraj C. Patel
}

'Department of Pediatrics, Levine Children's Hospital, Atrium Health, Charlotte, NC, USA

${ }^{2}$ Viracor Eurofins, Lee's Summit, MO, USA

Article Info

\section{Article Notes}

Received: September 27, 2020

Accepted: December 07, 2020

\section{${ }^{*}$ Correspondence:}

${ }^{*}$ Dr. Niraj C. Patel MD, MS, Chief Pediatric Infectious Disease and Immunology, Director, Charlotte Immunodeficiency Center, Levine Children's Hospital Atrium Health, Charlotte, NC, USA; Email: Niraj.Patel@atriumhealth.org

(C) 2020 Patel NC. This article is distributed under the terms of the Creative Commons Attribution 4.0 International License.

\section{Keywords:}

Pneumococcal avidity

Pneumococcal antibody

Immunoglobulin replacement

Pneumococcal vaccine polyvalent

Primary immunodeficiency

Recurrent infection

\section{ABSTRACT}

Measurement of pneumococcal antibody concentration is a frequently used parameter for functional antibody response to vaccination. Antibody concentration in response to vaccination and strength of antigen-antibody (avidity) interaction are both important measurements of functional antibody response. Both antibody concentration and avidity contribute to immunity against invasive pneumococcal disease. Higher avidity is correlated with increasing bactericidal activity and opsonophagocytosis. On the other hand, patients with lower pneumococcal avidity may be more likely to develop clinically significant pneumococcal sinopulmonary infections. Nine patients with recurrent bacterial respiratory infections were identified by retrospective chart review as having adequate pneumococcal antibody concentrations, but with low avidity for multiple serotypes following immunization with pneumococcal vaccine polyvalent (PPSV23). We assessed response with IgG replacement therapy in these patients. The mean number of serotypes with a normal antibody response $(>1.3 \mu \mathrm{g} / \mathrm{ml})$ among 9 children following immunization with pneumococcal vaccine polyvalent was 19.1 (range 12-22) of 23 serotypes while the mean number of serotypes with a normal avidity response $(\geq 1.0)$ was 4.7 (range $2-7)$ of 23 serotypes. Flow cytometry was performed for 8 of the 9 patients prior to starting SCIG replacement therapy. $100 \%$ of the cohort experienced a significant decrease in yearly infection rate after starting immunoglobulin replacement. This is the first study to assess the clinical response to immune globulin replacement in patients with normal pneumococcal antibody response but poor pneumococcal avidity, and suggests that patients with poor pneumococcal avidity but apparent normal response by pneumococcal antibody following PPSV23 may benefit from IgG replacement therapy.

\section{Abbreviations}

IgG, immunoglobulin; IVIG, intravenous immunoglobulin; SCIG, subcutaneous immunoglobulin; PIDD, primary immunodeficiency diseases; PCV7, heptavalent pneumococcal conjugate vaccine; PCV13, 13-valent pneumococcal conjugate vaccine; PPSV, pneumococcal polysaccharide vaccine

\section{Introduction}

Primary immunodeficiency diseases (PIDD) are a group of genetic disorders involving absent or defective components of the immune system resulting in increased susceptibility to infections ${ }^{1-7}$. More than 400 known genetic causes for PIDD exist, and patients generally present with recurrent moderate to severe infections that often have a poor response to antibiotic treatment ${ }^{8}$. Measurement of serum immunoglobulins is widely considered part of an initial immune evaluation ${ }^{9-13}$. Because some patients produce 
nonfunctional antibodies or do not make an antibody response to certain antigens, measurement of specific antibody response to vaccines containing proteins or carbohydrates is important. While diphtheria and tetanus toxoid vaccines are commonly tested antibodies to proteins, pneumococcal polysaccharide vaccine (Pneumovax ${ }^{\circledR}$ or PPSV23) is the most commonly tested anticarbohydrate response. A protective (normal or adequate) response to each pneumococcal serotype is defined as a level greater than or equal to $1.3 \mu \mathrm{g} / \mathrm{ml}$ antibody, and a conversion from a nonprotective to a protective titer. Based on limited evidence, a normal response to PPSV23 for children from 24 months through 5 years of age is conversion of $50 \%$ or more of the serotypes tested with at least a 2 -fold increase in the titers ${ }^{14}$. For subjects aged 6 to 65 years, a normal response is defined as conversion of $70 \%$ of the serotypes tested with at least a 2 -fold increase in the titers ${ }^{14}$.

Although pneumococcal antibody concentration is one of the most frequently used parameters for functional antibody response following vaccination, strength of antigen-antibody (avidity) interaction is an important determinant of functional antibody response, and contributes to immunity against invasive pneumococcal disease ${ }^{15,16}$. A protective avidity response to each pneumococcal serotype is defined as greater than or equal to 1.0 in the pediatric population (reference rage 0.6 to 18 years $)^{16,17}$. Patients with lower pneumococcal avidity are more likely to develop clinically significant pneumococcal sinopulmonary infections, while higher avidity is correlated with increasing bactericidal activity and opsonophagocytosis ${ }^{17}$. Absent or poor response to childhood vaccines, in the setting of recurrent respiratory illnesses, may indicate an antibody deficiency and necessitate consideration of immunoglobulin replacement.

Immunoglobulin (IgG) replacement therapy, a standard and life-saving treatment, is licensed for administration by intravenous (IVIG) or subcutaneous (SCIG) routes in adults and children greater than two years of age with PIDD. Optimization of IgG therapy can lead to a reduction in the frequency and severity of serious bacterial infections and end-organ damage with an improved health-related quality of life ${ }^{9,18-28}$. SCIG is efficacious, can be administered at home, is associated with fewer systemic side effects than IVIG, and often requires no pre-medications ${ }^{29}$. The aims of this retrospective pilot study were to identify and evaluate children with recurrent bacterial sinopulmonary infections who had appropriate rise in pneumococcal antibody titers following immunization with PPSV23 but low response by avidity. Patients with recurrent bacterial respiratory infections were identified as having sufficient pneumococcal antibody concentrations, but with low avidity for multiple serotypes. We assessed response with IgG replacement therapy in these patients.

\section{Methods}

A retrospective chart review was performed of the immunodeficiency outpatient clinic at Atrium Health and included nine children with recurrent bacterial respiratory infections, normal or low immunoglobulin concentrations, and adequate pneumococcal antibody response but low pneumococcal avidity following vaccination with PPSV23. Inclusion criteria included pediatric patients less than 18 years of age with recurrent respiratory sinopulmonary infections, appropriate antibody response to PPSV23, and low pneumococcal avidity. Infections were determined both from documented primary care, emergency room visits, or outside medical records as well as parental report and included infections from birth to first dose of replacement immunoglobulin. Exclusion criteria included patients with poor response to pneumococcal antibody following administration of PPSV23, and geneticallydetermined primary immunodeficiency disease. Avidity for 23 pneumococcal serotypes was assessed by measuring antibody binding in the presence of thiocyanate as previously described ${ }^{17}$. Study assessments included patient demographics, pneumococcal serotype variability, infection characteristics, immune function parameters, clinical and laboratory course while being treated with IgG replacement, and adverse events of IgG treatment. All research was conducted according to the policies and procedure approved by the Institutional Review Board of Atrium Health.

\section{Results}

All nine patients presented by referral after having recurrent sinopulmonary infections. Patient demographics and immunologic characteristics are shown in Table 1 . The mean age of subjects was 10.1 (range 3 - 15) years. Five patients were male (56\%), and four patients were female (44\%). Six of 9 subjects were Caucasian. Two of the study subjects are siblings (patients \#8 and \#9). All patients had received all of the routine childhood immunizations. The average age of infection onset was 18 months (range 1 month to 7 years). Sinusitis was the most common reported infection followed by acute otitis media and then pneumonia. Flow cytometry was performed for 8 of the 9 patients prior to starting SCIG replacement therapy and was overall within normal limits.

As part of an immunologic evaluation, all nine patients received PPSV23 and demonstrated normal antibody concentrations but low avidity response (Figure 1A and B). Following routine childhood immunization with PCV13 but prior to receipt of pneumococcal vaccine polyvalent, the mean number of serotypes was only 4.6 (range 3-10) among 8 of 9 children. The mean number of serotypes with a normal antibody response $(>1.3 \mu \mathrm{g} / \mathrm{ml})$ among 9 children following immunization with pneumococcal 
Table 1: Patient demographics, immunologic, and infusion characteristics

\begin{tabular}{|c|c|c|c|c|c|c|c|c|c|c|c|}
\hline Patient & $\begin{array}{l}\text { Sex/ } \\
\text { Race }\end{array}$ & $\begin{array}{c}\text { Age at } \\
\text { diagnosis } \\
\text { (years) }\end{array}$ & $\begin{array}{l}\text { IgG/IgM/IgA } \\
\text { (mg/dL) }\end{array}$ & $\begin{array}{l}\text { CD3+ T } \\
\text { cells/uL }\end{array}$ & $\begin{array}{l}\text { CD4+ T } \\
\text { cells/uL }\end{array}$ & $\begin{array}{l}\text { CD8+ T } \\
\text { cells/uL }\end{array}$ & $\begin{array}{l}\text { CD19+ B } \\
\text { cells/uL }\end{array}$ & $\begin{array}{c}\text { CD56+16 NK } \\
\text { cells/uL }\end{array}$ & $\begin{array}{c}\text { Dose of SCIG } \\
\text { (mg/kg/ } \\
\text { week) }\end{array}$ & $\begin{array}{c}\text { Duration of } \\
\text { infusions } \\
\text { (years) }\end{array}$ & $\begin{array}{c}\text { Age at last } \\
\text { follow up } \\
\text { (years) }\end{array}$ \\
\hline 1 & $\mathrm{M} / \mathrm{W}$ & 3 & $1125 / 37 / 158^{*}$ & 2228 & 1362 & 660 & 443 & 543 & 129 & 2 & 6 \\
\hline 2 & F/AA & 3 & $940 / 64 / 54$ & 3094 & 2094 & 678 & 929 & 148 & 64 & 1 & 4.5 \\
\hline 3 & $\mathrm{M} / \mathrm{W}$ & 2 & $576 / 133 / 96$ & $892^{*}$ & $411^{*}$ & $430^{*}$ & $189 *$ & 221 & 104 & 2 & 4.5 \\
\hline 4 & $\mathrm{M} / \mathrm{W}$ & 11 & $687 / 31^{*} / 80$ & 2203 & 1239 & 633 & 627 & 223 & 105 & 2 & 14.5 \\
\hline 5 & F/W & 13 & $464 * / 72 / 67$ & 2556 & 1670 & 844 & 556 & 189 & 125 & 3 & 16 \\
\hline 6 & $\mathrm{M} / \mathrm{W}$ & 11 & 596/117/19* & $1158^{*}$ & 674 & 395 & $952^{*}$ & 222 & 120 & 1 & 12 \\
\hline 7 & F/W & 4 & $436 * / 38 / 103$ & 2615 & 1518 & 928 & 1055 & 337 & 112 & 5 & 11 \\
\hline 8 & F/AA & 11 & $852 / 102.4 / 102.4$ & 2186 & 1418 & 605 & 677 & 121 & $\begin{array}{c}\text { \#None } \\
\text { current due } \\
\text { to insurance } \\
\text { denial }\end{array}$ & 1 & 16 \\
\hline 9 & $\begin{array}{l}\mathrm{M} / \\
\mathrm{AA}\end{array}$ & 10 & 693.6/94.9/89.9 & 1862 & 1090 & 517 & 587 & 185 & $\begin{array}{l}\text { \#None cur- } \\
\text { rent due to } \\
\text { encephalitis } \\
\text { and combat- } \\
\quad \text { ive }\end{array}$ & 2 & 15 \\
\hline
\end{tabular}

*=abnormal value; \#=each patient was started on immunoglobulin, and then stopped related to various reasons. $A A=A f r i c a n-A m e r i c a n ; F=$ female; $M=$ male; SCIG = subcutaneous immunoglobulin; $W=$ White

\section{Antibody versus Avidity Response}

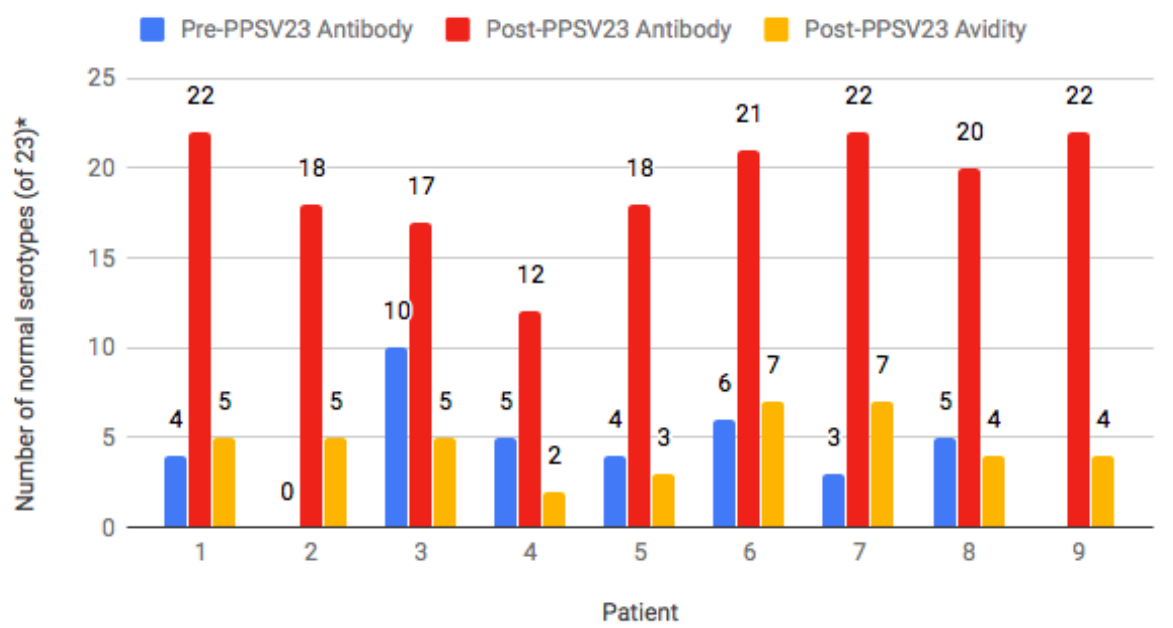

Figure 1A. Pneumococcal Avidity and Antibody Response following Immunization with PPSV23

* Normal serotypes: Antibody response $>1.3 \mu \mathrm{g} / \mathrm{mL}$; Avidity response $\geq 1.0 \mathrm{Al}$ (avidity index)

vaccine polyvalent was 19.1 (range 12-22) of 23 serotypes while the mean number of serotypes with a normal avidity response $(\geq 1.0$ ) was 4.7 (range $2-7$ ) of 23 serotypes (Table 2). All 9 patients maintained a robust response to vaccine when repeat pneumococcal antibody titers were measured 6 months post immunization. All patients had protective response to tetanus while 5 of 9 patients had normal response to diphtheria, and only 2 of 9 patients responded to Haemophilus influenzae vaccine.

The mean IgG level prior to starting replacement was $716.4 \mathrm{mg} / \mathrm{dL}$ (range 436-1125 mg/dL). Both IgM and IgA levels were normal in 6 of 9 (67\%) patients. IgG replacement for all 9 patients was administered subcutaneously with local reactions observed in 56\% of children and all reported as mild. No serious adverse events were reported. Patients started infusions between 2 to 13 years old (mean 7.7 years), and most patients have continued infusions for about 2.1 years to current. The mean SCIG weekly dosage was 122 (range 100-160) mg/kg/week and was administered either weekly $(n=8)$ or biweekly $(n=1)$. All 9 patients experienced a decrease in yearly infection rate after starting SCIG (Figure 2A and B). One patient had recurrence of infection frequency with lapse in insurance and subsequent denial of SCIG. 


\section{Average antibody versus avidity response}

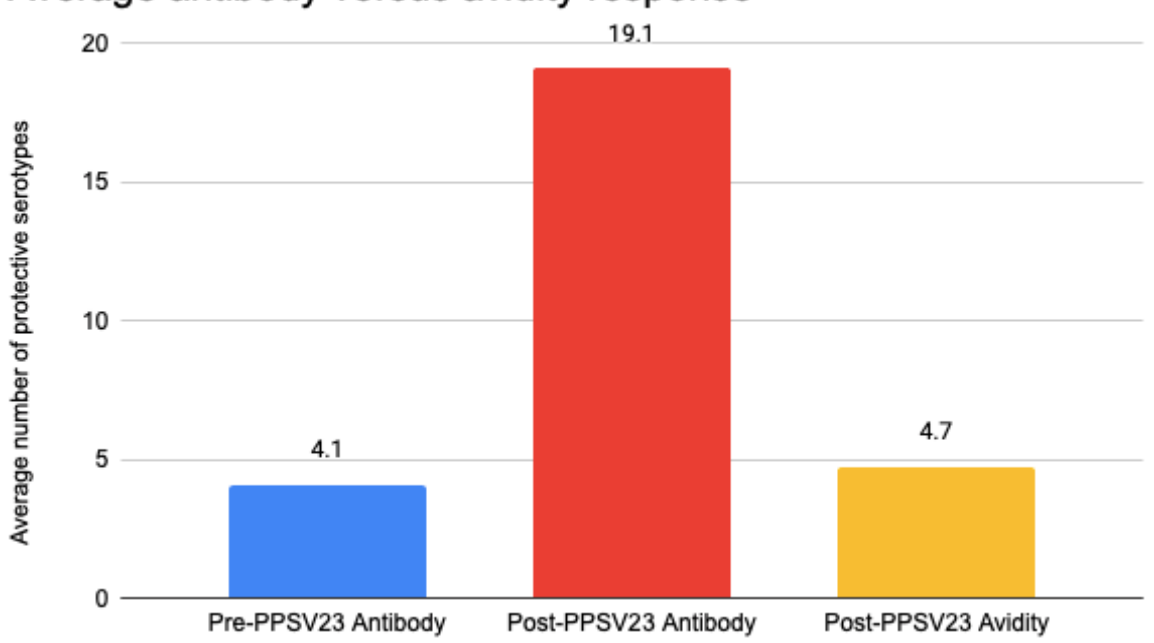

Figure 1B. Combined Average of Pneumococcal Serotypes following Immunization with PPSV23

Table 2: Patient response to protein and polysaccharide vaccines*

\begin{tabular}{|c|c|c|c|c|c|c|}
\hline Patient & $\begin{array}{c}\text { Tetanus } \\
(>0.1 \text { IU/ } \\
\mathrm{mL})\end{array}$ & $\begin{array}{l}\text { Diphtheria } \\
\text { (>0.1 IU } / \mathrm{mL})\end{array}$ & $\begin{array}{l}\text { Haemophilus } \\
\text { influenzae } \\
(>1.0 \mu \mathrm{g} / \mathrm{mL})\end{array}$ & $\begin{array}{l}\text { Streptococcus pneumoniae } \\
\text { antibodies, } 23 \text { serotypes ( }>1.3 \\
\mu \mathrm{g} / \mathrm{mL} \text { ) after } 4 \text { doses of PCV13 } \\
\text { (serotypes present in PCV13) }\end{array}$ & $\begin{array}{c}\text { Streptococcus pneu- } \\
\text { moniae antibodies, } 23 \\
\text { serotypes (>1.3 } \mathrm{\mu g} / \mathrm{mL} \text { ) } \\
\text { following receipt of } \\
\text { PPSV23 }\end{array}$ & $\begin{array}{l}\text { Streptococcus pneumoniae } \\
\text { avidity, } 23 \text { serotypes ( } \geq 1.0 \text { ) } \\
\text { following receipt of PPSV23 }\end{array}$ \\
\hline 1 & Normal & Normal & Low $(0.13)$ & $\begin{array}{c}10 / 23 \\
(3,5,14,19 \mathrm{~A}, 23 \mathrm{~F}, 17 \mathrm{~F}, 18 \mathrm{C}, 19 \mathrm{~A})\end{array}$ & $17 / 23$ & $4 / 23$ \\
\hline 2 & Normal & Normal & Low $(0.86)$ & NA & $22 / 23$ & $4 / 23$ \\
\hline 3 & Normal & Low $(0.05)$ & Low $(0.11)$ & $0 / 23$ & $18 / 23$ & $5 / 23$ \\
\hline 4 & Normal & Normal & Low $(<0.11)$ & $6 / 23(3,19 F, 19 A)$ & $21 / 23$ & $7 / 23$ \\
\hline 5 & Normal & Normal & Low & $5 / 23(1,14,19 F)$ & $20 / 23$ & $2 / 23$ \\
\hline 6 & Normal & Low $(0.03)$ & Low $(<0.11)$ & $4 / 23(3,6 B, 9 N, 19 A, 19 A, 19 F)$ & $17 / 23$ & $3 / 23$ \\
\hline 7 & Normal & Normal & Normal & $5 / 14(7 F, 19 F)$ & $12 / 23$ & $2 / 23$ \\
\hline 8 & Normal & Low (0.1) & Low $(<0.11)$ & $4 / 23(9 V, 18 C, 19 A)$ & $22 / 23$ & $5 / 23$ \\
\hline 9 & Normal & Low $(0.07)$ & Normal & $3 / 23(14,18 C, 23 F)$ & $22 / 23$ & $7 / 23$ \\
\hline
\end{tabular}

*6A (present in PCV13) was not included in Streptococcus pneumoniae 23 panel; NA = not available; PCV13 = 13-valent pneumococcal conjugate vaccine; PPSV23 = pneumococcal polysaccharide vaccine

\section{Infection rates pre- and post- IVIG}

Pneumonia, sinusitis, and acute otitis media

Pre-IVIG

Post-IVIG

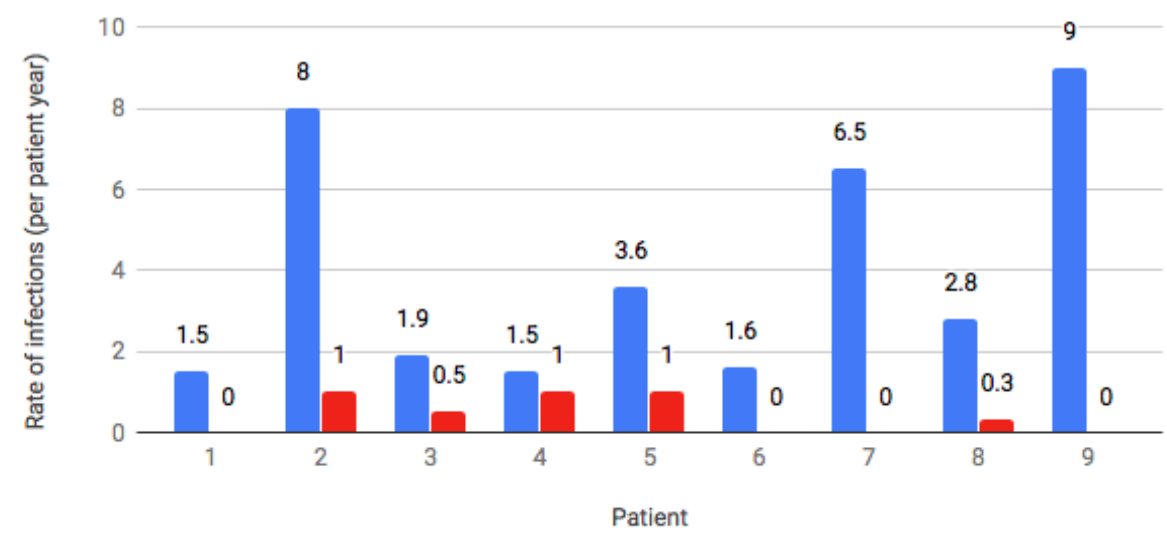

Figure 2A. Infection Rates Before and After IgG Replacement Therapy*

*= Infections included pneumonia, sinusitis, acute otitis media 


\section{Infection rates}

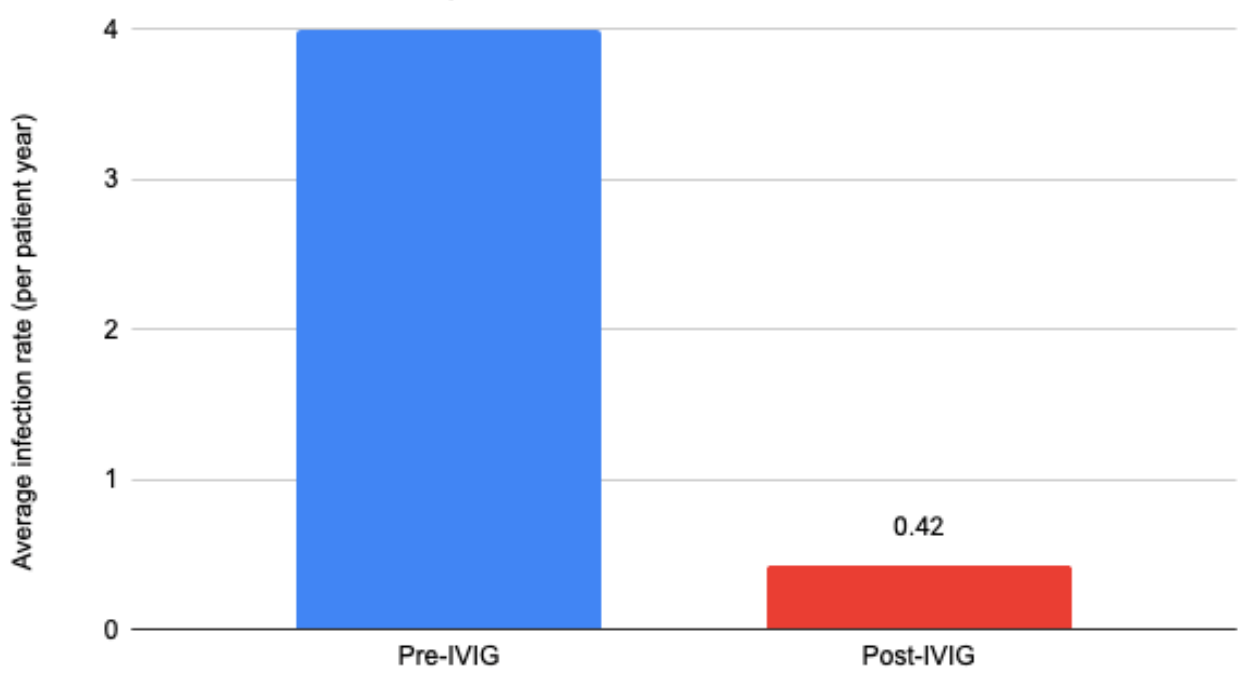

Figure 2B. Infection Rate (All Infections) Before and After IgG Replacement Therapy

\section{Discussion}

This retrospective pilot study compares pneumococcal antibody concentrations and avidity in patients with recurrent sinopulmonary infections following receipt of PPSV23, as well as assessment of clinical response to immune globulin replacement in patients with normal pneumococcal antibody response but low pneumococcal avidity. The patients in this cohort had pneumococcal avidity testing post-PPSV23 that showed low response, but it would be interesting and important to assess if avidity is altered by SCIG. One study notes both high antibody responses and avidity in three serotypes up to 4 years after immunization with heptavalent pneumococcal conjugate vaccine (PCV7) suggesting prolonged protective immunity ${ }^{3}$. Interestingly, in this study, we found stronger avidity in serotypes in the 13-valent pneumococcal conjugate vaccine (PCV13). Four patients shared positive avidity results for serotypes 7F, 11A, 19A, and $23 \mathrm{~F}$. All of those serotypes but $11 \mathrm{~A}$ are included in PCV13. This is in contrast all nine patients having low avidity $(<1.0)$ to five serotypes including 1, 8, 9N, 12F, and 17F. Of those 5 serotypes, only serotype 1 is included in PCV13 while the rest are only included in PPSV23. While low antibody avidity may be associated with vaccine failure, there is not enough data to determine whether this is true for pneumococcal vaccines ${ }^{3}$. Other studies suggest that for a variety of reasons avidity functions as another factor in differentiating a patient's immunity to invasive pneumococcal disease ${ }^{4,5}$. This also raises the question of which serotypes are more represented in immune globulin and if that will ultimately affect avidity outcomes after receiving SCIG.

Limitations of this retrospective pilot study include small sample population and recall bias. Patient/parent self-reporting of infections may have underestimated the number of infections after immunoglobulin therapy was initiated or inability or unwillingness to seek medical attention due to insurance type of socioeconomic demographics. The infections were documented by primary care physicians or per parental record, and may have been affected by wrong diagnosis and overprescribing of antibiotics, all which could affect the infection rate.

Larger studies are needed to determine the generalizability of these findings. A larger sample size could assess whether increased infections are associated with low pneumococcal avidity, and whether a significant decline in infection rate occurs following immunoglobulin replacement in these patients. Prospective studies could benefit from improved data collection on infections rates in a consistent and more uniform manner. Future research is also needed to assess pneumococcal avidity after receiving SCIG to determine if avidity is altered or improved by immune globulin replacement.

In summary, pneumococcal avidity should be considered as a tool for patients with recurrent infections despite normal pneumococcal antibody response. While the complete series of conjugate PCV13 vaccine was given to all patients, this study demonstrates the need to assess response to polysaccharide PPSV23. Our study suggests that patients with discordant pneumococcal antibody and avidity response should be considered for immune globulin replacement. Patients who were placed on IgG therapy had a marked reduction in bacterial respiratory infections.

Although the make-up of IVIG is well-known now and antibody titers can be tested in each formulation, no studies have tested disease-specific avidity of the IgG antibodies within IVIG. Pneumococcal serotypes, particular those that most commonly cause invasive infection in children, 
have been detected at protective levels in intravenous and subcutaneous preparations of immunoglobulin ${ }^{30-32}$. The patients in this cohort had pneumococcal avidity testing post-PPSV23 that showed poor response, but the avidity has not yet been repeated after starting immune globulin replacement.

\section{Conclusions}

In PIDD patients with recurrent sinopulmonary infections with normal antibody response to pneumococcal vaccine polyvalent, measurement of pneumococcal avidity identified patients with poor pneumococcal antibody function. This is the first study to assess the clinical response to immune globulin replacement in patients with normal pneumococcal antibody response but poor pneumococcal avidity, and suggests that patients with poor pneumococcal avidity but apparent normal response by pneumococcal antibody following PPSV23 may benefit from IgG replacement therapy.

\section{Conflict of Interest}

N.C.P. is on the Speakers Bureau for Takeda, CSL Behring, and Horizon Therapeutics, and receives research support from Takeda and CSL Behring.

\section{References}

1. Buckley RH. Primary immunodeficiency diseases due to defects in lymphocytes. N Engl J Med. 2000; 343: 1313-24.

2. Chapel H, Geha R, Rosen F. Primary immunodeficiency diseases: an update. Clin Exp Immunol. 2003; 132: 9-15.

3. Ochs HD, Smith CIE, Puck JM. Primary immunodeficiency diseases: a molecular and genetic approach. 3rd ed. New York: Oxford University Press Inc, USA: 2014.

4. Al-Herz W, Bousfiha A, Casanova JL, et al. Primary immunodeficiency diseases: an update on the classification from the international union of immunological societies expert committee for primary immunodeficiency. Front Immunol. 2014; 5: 162.

5. Cunningham-Rundles C, Bodian C. Common variable immunodeficiency: clinical and immunological features of 248 patients. Clin Immunol. 1999; 92: 34-48.

6. Bousfiha AA, Jeddane L, Ailal F, et al. A phenotypic approach for IUIS PID classification and diagnosis: guidelines for clinicians at the bedside. J Clin Immunol. 2013; 33(1): 1-7.

7. McCusker C, Warrington R. Primary Immunodeficiency. Allergy Asthma Clin Immunol. 2011; 7(Suppl 1):S11.

8. Tangye SG, Al-Herz W, Bousfiha A,et al. Human inborn errors of immunity: 2019 update on the classification from the international union of immunological societies expert committee. J Clin Immunol. 2020; 40(1): 24 .

9. Bonilla FA, Khan DA, Ballas ZK, et al. Joint Task Force on Practice Parameters, representing the American Academy of Allergy, Asthma \& Immunology; the American College of Allergy, Asthma \& Immunology; and the Joint Council of Allergy, Asthma \& Immunology. Practice parameter for the diagnosis and management of primary immunodeficiency. J Allergy Clin Immunol. 2015; 136(5): 1186-205.

10. Lehman H, Hernandez-Trujillo V, Ballow M. Diagnosing primary immunodeficiency: a practical approach for the non-immunologist. Curr Med Res Opin. 2015; 31(4): 697-706.
11. Locke BA, Dasu T, Verbsky JW. Laboratory diagnosis of primary immunodeficiencies. Clin Rev Allergy Immunol. 2014: 46(2): 154-68.

12. Reust, CE. Evaluation of primary immunodeficiency disease in children. Am Fam Physician. 2013; 87(11): 773-8.

13. De Vries E, Driessen G. Educational paper: primary immunodeficiencies in children: a diagnostic challenge. Eur J Pediatr. 2011; 170(2): 169-77.

14. Orange JS, Ballow M, Stiehm ER, et al. Use and interpretation of diagnostic vaccination in primary immunodeficiency: a working group report of the Basic and Clinical Immunology Interest Section of the American Academy of Allergy, Asthma \& Immunology. J Allergy Clin Immunol. 2012; 130(3 Suppl): S1-24.

15. Cohn M, Langman RE. The protection: the unit of humoral immunity selected by evolution. Immunol Rev. 1990; 115: 11-147.

16. Usinger WR, Lucas AH. Avidity as a determinant of the protective efficacy of human antibodies to pneumococcal capsular polysaccharides. Infect Immun. 1999; 67(5): 2366-2370.

17. Fried AJ, Altrich ML, Liu H, et al. Correlation of pneumococcal antibody concentration and avidity with patient clinical and immunologic characteristics. J Clin Immunol. 2013; 33(4): 847-56.

18. Quartier P, Debre M, De Blic J, et al. Early and prolonged intravenous immunoglobulin replacement therapy in childhood agammaglobulinemia: a retrospective survey of 31 patients. J Pediatr. 1999; 134: 589-96.

19. Busse PJ, Razvi S, Cunningham-Rundles C. Efficacy of intravenous immunoglobulin in the prevention of pneumonia in patients with common variable immunodeficiency. J Allergy Clin Immunol. 2002; 109: 1001-4.

20. Church JA, Borte M, Taki H, et al. Efficacy and safety of Privigen $®$ in children and adolescents with primary immunodeficiency. Pediatr Asthma Allergy Immunol. 2009; 22: 53-62.

21. Eijkhout HW, van der Meer JW, Kallenberg CG, et al. The effect of two different dosages of intravenous immunoglobulin on the incidence of recurrent infections in patients with primary hypogammaglobulinemia. A randomized, double-blind, multicenter crossover trial. Ann Intern Med. 2001; 135: 165-74.

22. Stein MR, Nelson RP, Church JA, et al. Safety and efficacy of Privigen $®$, a novel $10 \%$ liquid immunoglobulin preparation for intravenous use, in patients with primary immunodeficiencies. J Clin Immunol. 2009; 29: $137-44$

23. Abrahamsen TG, Sandersen H, Bustness A. Home therapy with subcutaneous immunoglobulin infusions in children with congenital immunodeficiencies. Pediatrics. 1996; 98: 1127-31.

24. Berger M. Principles of and advances in immunoglobulin replacement therapy for primary immunodeficiency. Immunol Allergy Clin North Am. 2008; 28(2): 413-37.

25. Gardulf A, Nicolay U, Asensio O, et al. Rapid subcutaneous IgG replacement therapy is effective and safe in children and adults with primary immunodeficiencies - a prospective, multi-national study. J Clin Immunol. 2006; 26: 177-85.

26. Ochs HD, Gupta S, Kiessling, et al. Safety and efficacy of selfadministered subcutaneous immunoglobulin in patients with primary immunodeficiency diseases. J Clin Immunol. 2006; 26: 265-273.

27. Berger M. Subcutaneous administration of IgG. Immunol Allergy Clin North Am. 2008: 28(4): 779-802.

28. Patel NC, Gallagher JL, Ochs HD, et al. Subcutaneous immunoglobulin replacement therapy with Hizentra ${ }^{\circledR}$ is safe and effective in children less than 5 years of age. J Clin Immunol. 2015; 35(6): 558-65.

29. Patel NC. Individualized immunoglobulin treatment in pediatric patients with primary humoral immunodeficiency disease. Pediatr Allergy Immunol. 2018; 29(6): 583-588. 
30. Tuerlinckx D, Florkin B, Ferster A, et al. Pneumococcal antibody levels in children with PID receiving immunoglobulin. Pediatrics. 2014; 133 (1): e154-e162

31. Takahashi Y, Ishiwada N, Hishiki H, et al. IgG levels against 13-valent pneumococcal conjugate vaccine serotypes in non pneumococcal conjugate vaccine immunized healthy Japanese and intravenous immunoglobulin preparations. J Infect Chemother. 2014; 20(12): 794-8.

32. Abghari PF, Poowuttikul P, Secord E. Pneumococcal antibody titers: a comparison of patients receiving intravenous immunoglobulin versus subcutaneous immunoglobulin.Glob Pediatr Health. 2017 Feb 21; 4: $1-6$. 